IEEE Engineering Education Demand Summit

\title{
AN INNOVATIVE LINKAGE OF CURRICULA DESIGN, POWER ENGINEERING INDUSTRIES AND UNIVERSITIES IN QUEENSLAND AUSTRALIA TO PROMOTE ENGINEERING EDUCATION
}

\author{
Nasser Hosseinzadeh (Member IEEE) and Steven Senini (Member IEEE) \\ Central Queensland University \\ North Rockhampton, Queensland, Australia
}

\begin{abstract}
The demand for engineers and their educators has been continuously growing in Australia. In recent years, the academia and industry leaders have proposed and implemented a number of strategies to meet the demand. One of these strategies in the State of Queensland has been the formation of Power Engineering Alliance (PEA), which brings together Industry and University Partners with a common interest in education, research and professional development associated with Power Engineering. The Objectives of the PEA are to boost the quality and number of engineering graduates with the skills and motivation for a career in power engineering, and to contribute to their ongoing professional development. Central Queensland University (CQU) has been one of the leading University Partners to this alliance. CQU has been recognised as a provider of engineering teaching excellence to the Central Queensland region and beyond.
\end{abstract}

\section{INTRODUCTION}

Universities and industries have undergone a long period of low interest from the young generations towards undergraduate engineering programs, especially electrical power engineering. For example, in the United States of America undergraduate engineering enrollments reached its all-time high in 1983, after which a steady decline in enrolments occurred [1]. Other advanced countries have had a similar situation. In the United States, it seems that the peak for electrical engineering (EE) normally happens two years earlier than the overall undergraduate engineering programs. The engineering-wide enrolments reached a low in 1998 in North America; the EE low occurred in 1996. The recovery of engineering enrolments has been slow [1].

The situation in power engineering is more fuzzy because reliable statistics are not well documented. The statistics are fuzzy partly because there is no universal definition of a submajor of EE undergraduate students. However, the percentage of undergraduate electrical engineering students committed to electric power in the USA has been declining from 1978 to 2001. It seems that students have shown more interest in the power engineering area since 2001. In the 1970s, power represented between 10 and 15\% of the undergraduate EE enrolments; in 1992 it was 7\%, and its minimum occurred in 2001 at about 5.9\%. The 2002 data showed that the trend was reversed back to approximately $7 \%$ [1]. 
There is normally about four or five years delay between the time that students enrol and the time when they graduate. Therefore, it is naturally expected that the percentage of power engineering graduates compared to the engineering-wide graduates should have already started to increase in the US in 2006 and 2007. The authors do not have the statistic data to confirm this. However, it has been reported that in 2003 the intensive reduction in engineering personnel at utilities gave the power engineering field a black eye [2]. It seems that this reduction and some other human factors were among the main reasons for the big blackout of August 2003 in the Northern American Continent. On the other hand, the blackout of 2003 brought the problem to the attention of politicians. Gross et al have stated, "the 2003 mega-blackout produced keen interest in the reliability of the interconnected grid” [1], [3]. The security of the North American interconnected power system has been heavily studied since the occurrence of that blackout.

In Australia, the shortage of engineering skills, particularly shortage of power engineers, illustrated the problem to the industry leaders. Consequently, the power engineering industries started to seriously support the universities in Australia to promote power engineering fields since 2004. Particularly, in the State of Queensland, a Power Engineering Alliance (PEA) was established, which comprises from leading industries and universities in Queensland. The Objectives of the PEA are to boost the quality and number of engineering graduates with the skills and motivation for a career in power engineering, and to contribute to their ongoing professional development.

As the requirements of the stakeholders in the engineering education process has changed, Central Queensland University (CQU) has adapted its offerings and incorporated new, brave and innovative approaches to learning and teaching. CQU currently offers electrical engineering undergraduate programs at Associate Degree of Engineering (ADE), Bachelor of Engineering Technology (BET) and Bachelor of Engineering (BE) levels. A particular area of interest is the Bachelor of Engineering cooperative/ Diploma of Professional Practice (BE/Co-op) with the latter element of this dual award specifically recognising and credentialing professional engineering practice incorporated in the program, [4]. The program philosophically relies on project based learning (PBL) methodology in facilitating student learning.

This paper outlines the history of innovation at CQU, the previous program structure and a new curriculum design, which has occurred as a major review of undergraduate engineering programs. Electrical engineering program plans will be used as examples of the new curricula for undergraduate engineering education. In addition to the increased integration of the programs, the new electrical engineering program has a stronger emphasis on Project/Problem Based delivery across the suite of programs. It is believed that these new programs and associated assessment/delivery processes will shape the future of engineering education into the new millennium. The new curricula enhance student learning by introducing innovations in course design, teaching methodologies and learning resources that ensure students have the skills, knowledge and attributes they need to enter the engineering profession. A strong linkage is formed through 
collaborative research projects, industry training courses and on-going networks to ensure student learning is industry-relevant and real-world focused. This includes:

- ensuring course content is relevant and up-to-date

- developing and implementing pedagogies that focus on active learning and problem solving

- collaboration with industry to ensure undergraduate projects have a real-world basis and/or application

- development of cutting-edge learning facilities and resources that are congruent with industry conditions.

By making classroom learning experiences industry-relevant, interactive and studentcentred educators will be able to influence, motivate and inspire student learning. The development of curricula and resources are based on not only engineering technical requirements and current industry practice, but also of contemporary pedagogical approaches and active learning principles.

At CQU, philosophical review of the BE (Co-op) program commenced in 1996. The aim of the review was to consider an alternative, improved learning paradigm that complemented co-operative education. A national study was co-incidentally being undertaken by the Institution of Engineers, Australia (IEAust), which culminated in a 1996 report, [4], calling for significant changes in how engineering programs in Australia were to prepare students for their engineering careers.

In 1998 a new program philosophy utilising Project Based Learning (PBL) was introduced to better prepare students for their industry placements. As a result, in 2004 the program evolved into a fully integrated BE (Co-op)/DipProfPrac with the latter element of this dual award specifically recognising professional engineering practice incorporated in the program, [4].

In 2005, as part of the regular continuous improvement cycle, the engineering programs at Central Queensland University commenced another major review. The program review outlined a broad philosophy which governed the structure and delivery of courses in all discipline plans. Within this philosophy, Discipline Groups were delegated the task of devising the program content for their discipline plans, under the guidance of the Discipline Leaders. The outcomes of this review for the electrical discipline are the main focus of this paper.

\section{THE STATUS QUO IN 2005}

When the review commenced in 2005, CQU was offering a selection of programs including BET and two Professional Engineering Programs (BE standard and BE(Coop)/DipProfPrac). These programs were accredited with Engineers Australia. An Associate Degree of Engineering (ADE) Program was designed as an exit award from the BET program. The ADE program was closely aligned with the BET program such that it comprised the first two years of the BET program. This allowed BET students to exit for an ADE Certificate at the end of second year or, alternatively for those who initially 
enrolled in the ADE program, to have a direct articulation path from the ADE into the third year of the BET with one year of additional study to complete the BET program (on a part time basis). The ADE and BET suite of programs were only available in distance flexible mode, as the number of internal students in the higher year levels were not sufficient to run these courses on campus. This problem was compounded by the use of specialisation electives, further diluting the student numbers in each course.

Among these undergraduate programs, the $\mathrm{BE}(\mathrm{Co}-\mathrm{op}) / \mathrm{DipProfPrac})$ has been referred to as the flagship program. This program is a four year professional engineering degree combined with two work placements, six months each, and additional professional practice courses. The nominal program length is four and a half years. The standard BE does not include the work placements and professional practice courses.

The BE programs had a common first year across three disciplines, namely Civil Engineering, Electrical Engineering and Mechanical Engineering. The later years included a few common courses (mostly mathematics and management courses) and the remaining courses were discipline specific. These programs incorporated PBL as a core philosophy of learning and teaching. In any given term, $50 \%$ of the students' course load was delivered in a PBL mode. Over the eight years since this structure was introduced, it has proven to be very successful in developing graduates who are professionally ready for the workplace as well as technically competent.

The BE and BE (Co-op) programs were only available internally. This made articulation between the BET and the BE difficult for students, as they were required to change study mode from external to internal. Often this did not suit their personal circumstances, and they were left to seek other options for the articulation.

\section{CORE DRIVES OF THE REVIEW}

The weaknesses identified in the previous analysis were core drivers in the reviewed program structure. Additionally, it was desired to preserve the strengths of the CQU programs identified in the 2002 accreditation [5]. The key strengths were:

The co-op Program and relationships with industry partners

The Project Based delivery in the Bachelor of Engineering programs

The existing external delivery of ADE and BET

The core drivers in the review process may then be summarized as:

Economic Sustainability: This could be achieved by rationalising courses and reducing the number of low enrolment courses.

More flexible articulation pathways

Continuing innovation and leading edge educational programs

\section{NEW PROGRAM STRUCTURES}

Towards these goals, the Associate Degree of Engineering has now been decoupled from the BET offering. The required graduate attributes of the associate program identify an independent program with clearly defined articulation. The decoupling of ADE from the 
BET program allows the ADE to be completely tailored to the needs of industry. The courses can be much more practically focussed without compromising the future needs of the students who will continue into the BET. Table 1 shows two of the three electrical specialisations in ADE level. The number of common courses has been reduced, allowing electrical students to develop a greater degree of discipline knowledge.

Table 1. Structure of the Revised Electrical ADE Program.

\begin{tabular}{|c|c|c|}
\hline Yr & Term 1 & Term 2 \\
\hline \multicolumn{3}{|c|}{ Common First Year } \\
\hline \multirow[t]{2}{*}{1} & Professional Engineering Communication & Engineering Materials \\
\hline & Mechanics & Energy and Electricity \\
\hline \multirow[t]{2}{*}{2} & Engineering Drafting & Computer Aided Drafting \\
\hline & Technology Mathematics & Measurement and Data Analysis \\
\hline \multicolumn{3}{|c|}{ Electrical (Power and Machines) } \\
\hline \multirow[t]{2}{*}{3} & Electrical Components and Modelling & Sustainability Technology and the Environment \\
\hline & Electrical Machines and Drives & Electrical/Electronic Circuit Computations \\
\hline \multirow[t]{2}{*}{4} & Computer Aided Drafting and Design (Electrical) & Electrical Power Systems \\
\hline & Electrical Services and Protection & Electrical Power System Modelling \\
\hline \multicolumn{3}{|c|}{ Electrical (Control and Instrumentation) } \\
\hline \multirow[t]{2}{*}{3} & Electrical Components and Modelling & Sustainability Technology and the Environment \\
\hline & Electronic Devices and Applications & Electrical/Electronic Circuit Computations \\
\hline \multirow[t]{2}{*}{4} & Computer Aided Drafting and Design (Electrical) & Control Technology \\
\hline & Introductory Electronic Communications & Instrumentation and Transducers \\
\hline
\end{tabular}

The BET has been redeveloped to align with new directions of Engineers Australia in defining the role of the technologists. The wording of the documentation indicates that a Technologist may be the equal of an Engineer in their defined area of specialty, but the skills of a Technologist are not necessarily transferable to different areas of the discipline, or different industries. The revised BET program shares most of the courses with the BE program, allowing more flexible options for students. The use of different BE course combinations has allowed three electrical specialisations to be retained without additional courses being required. The revised structure for two streams (Power and Control) is shown in Table 2. The timelines in this program are indicated for part-time study, as this is currently the most popular option. The BET program contains a greater amount of Computer Aided Design (CAD) content compared to the BE graduates, and a slightly lower amount of mathematics. All courses will be available internally and externally, allowing students to select the study mode most suited to their personal circumstances and to change that mode as their circumstances change.

For the BE(Co-op) program associated with the Diploma of Professional Practice the major change is a redistribution of course content and outcomes. The new program still has a completely common first year, but the commonality has now been extended to encompass $75 \%$ of the second year courses, as shown in Table 3 . The remaining $25 \%$ of the courses in second year are discipline based. As CQU is a multi-campus university, this change allows the second year offering to be extended to the other campuses. 
Table 2. Structure of the Revised Electrical BET Program

\begin{tabular}{|c|c|c|}
\hline Yr & Term 1 & Term 2 \\
\hline \multicolumn{3}{|c|}{ Common First Year } \\
\hline 1 & Engineering Skills 1 (12uc) & Engineering Skills 2 (12uc) \\
\hline \multirow[t]{2}{*}{2} & Engineering Physics $A$ & Engineering Physics $B$ \\
\hline & Engineering Foundation Mathematics & Engineering Mathematics \\
\hline \multicolumn{3}{|c|}{ Electrical (Power and Machines) } \\
\hline 3 & Materials and Processes (12uc) & Engineering Design (12uc) \\
\hline \multirow[t]{2}{*}{4} & Electrical Circuit Analysis & Computer Aided Drafting \\
\hline & Analogue and Digital Electronics & Electrical Power Engineering \\
\hline \multirow{2}{*}{5} & Machines, Drives and Control (12uc) & Engineering Project Management \\
\hline & & Technology Project Planning \\
\hline \multirow{2}{*}{6} & Technology Project Implementation & Power System Analysis (12uc) \\
\hline & Power System Protection & \\
\hline \multicolumn{3}{|c|}{ Electrical (Control and Instrumentation) } \\
\hline 3 & Materials and Processes (12uc) & Engineering Design (12uc) \\
\hline \multirow[t]{2}{*}{4} & Electrical Circuit Analysis & Computer Aided Drafting \\
\hline & Analogue and Digital Electronics & Embedded Microcontrollers \\
\hline \multirow{2}{*}{5} & Control Systems (12uc) & Instrumentation and Transducers \\
\hline & & Technology Project Planning \\
\hline \multirow{2}{*}{6} & Signal Processing Systems & Engineering Project Management \\
\hline & Technology Project Implementation & Electronic Communications \\
\hline
\end{tabular}

Table 3. Structure of the Revised Electrical BE(Coop)/DipProfPrac.

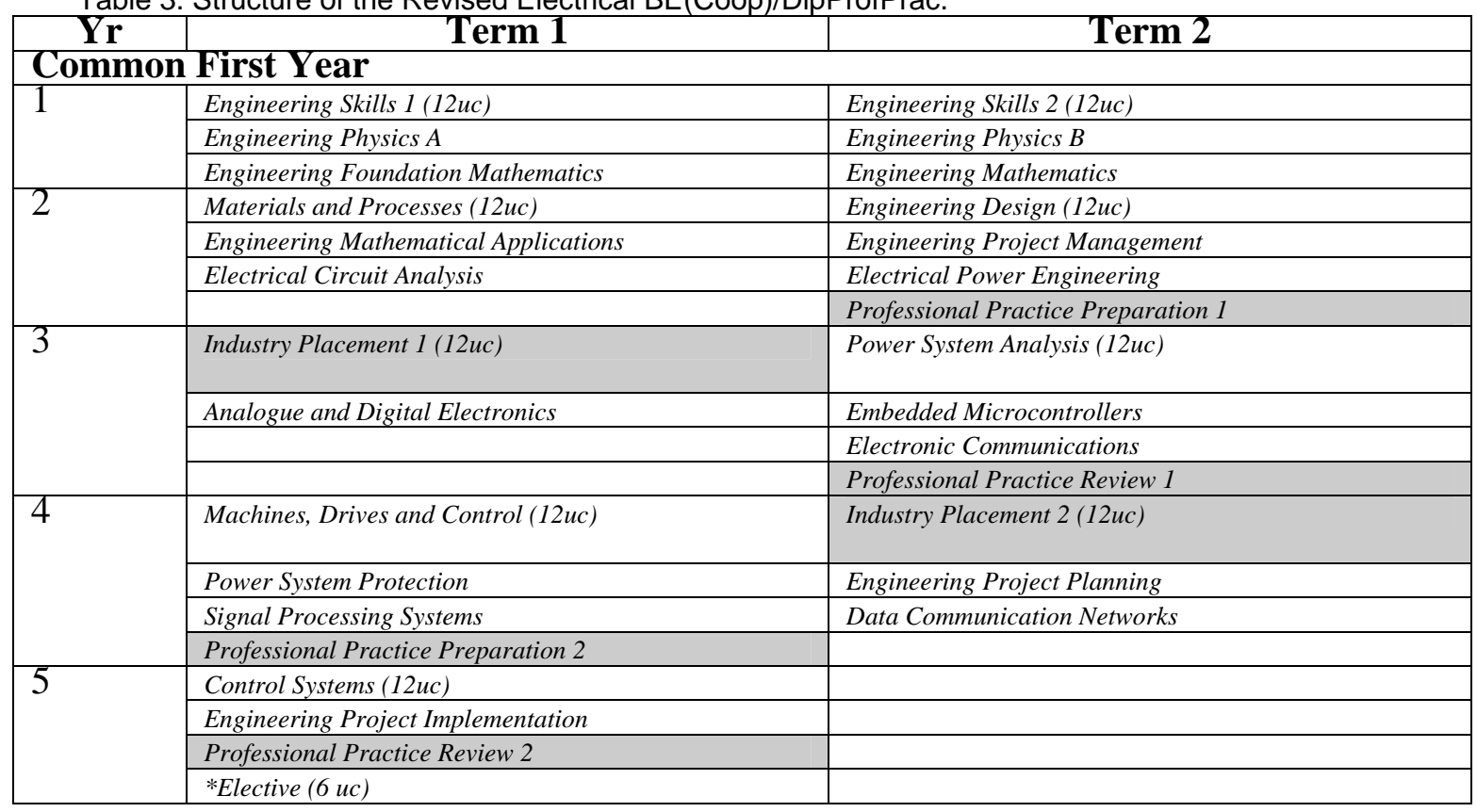


The course content has been redistributed and integrated with professional practice components to meet the full spectrum of Graduate Attributes in an explicit and clearly identifiable manner. The shaded cells in Table 3 represent those courses which are associated with the Diploma of Professional Practice. The BE standard Program shares the same structure as the plan shown in Table 3, but with the Shaded cells removed, and the other courses redistributed into a four year delivery. These second year courses are common with mechanical and civil disciplines except for the two electrical courses.

This alignment of the BET and BE allows clear articulation between the two programs. Students completing a BET will only be required to do the additional courses from the $\mathrm{BE}$ program which were outside the specialisation plan chosen. Typically this will mean an additional 1.5 to 2 years of full time study. The sharing of courses between the BE and the BET programs will allow more flexible options for students. All courses will be available internally and externally, allowing students to select the study mode most suited to their personal circumstances and to change that mode as their circumstances change.

At the time being, two PBL courses are being developed by the authors. These courses, namely Power System Analysis and Electrical Machines, Drives and Control are developed for third year or fourth year offerings. Both these courses are 12 units of credit, which is equivalent to two conventional courses, and will be offered in PBL This has involved the creation of a Power System Laboratory and a Machines and Drives Laboratory. These are innovative learning resources designed to enable students to work with the commercial software packages used in the power industry and learn by PBL the main concepts in power system analysis and also to learn about machines and their control gears by doing projects in the Electrical Machines Laboratory. PEA has supported these new developments by sharing the required funds.

The Power System Laboratory and Electrical Machines Laboratory are state-of-the-art learning resources to give students access to commercial software packages used in power utility companies and electrical machines and their drives. Although similar laboratories can be found in many other universities across the globe, the way that they are being used to conduct PBL methodology in facilitating deep learning of students based on real world problems make them different and perhaps unique at this stage of time.

Particularly, for Power System Analysis, projects will be defined in the following areas.

Development of power simulation laboratory using the commercial software packages

Load flow studies

Fault studies

Renewable energy systems

Alternative energy, embedded generation, co-generation, and dispersed resources

Power quality

Hybrid electric car

Energy management

Optimal planning, especially in a deregulated electricity market environment 
It is expected that these topics offered in a PBL mode will attract more undergraduate engineering students to electrical power systems area.

\section{CONCLUSIONS}

The review of Engineering Programs at CQU has resulted in an improved set of programs. The new programs have reduced the number of courses required, thus improving the economic sustainability of the programs. The articulation pathways for the programs are much more clearly defined as the programs were developed from the top down, with this goal. The extension of the delivery of all courses to external has also improved the flexibility for students to select their mode of study to suit their circumstances.

The program review resulted in the integration of Project Based Learning and Flexible Delivery across the entire engineering undergraduate program spectrum and has extended the innovation of previous reviews and continuous improvement processes into all the engineering programs at CQU. The new programs and associated assessment/delivery processes will shape the future of engineering education in Central Queensland and contribute to it across Australia and internationally in the new millennium. The program is expected to produce world class professional engineers, technologists and associates that are industry ready and highly sought after.

\section{REFERENCES}

[1] Heydt G. T. and V. Vittal, “Feeding our profession”, IEEE Power \& Energy Magazine, vol. 1, issue 1, Jan/Feb 2003, pp 38-45.

[2] Gross G., Heydt G., Sauer P. and Vittal V., "Some reflections on the status and trends in power engineering education”, IERE Workshop: The next generation of power engineers and researchers, Montreal, Quebec, Canada, 10 Oct. 2003.

[3] Sauer P. W., Heydt G. T. and Vittal V., "The state of electric power engineering education,” IEEE Transactions on Power Systems, Special section on Education, 2004

[4] Jorgensen D., Howard P., 2005, “Ten years in the making - a Project Based Learning, Professional Practice, Co-operative Education Program”, Proceedings of the $14^{\text {th }}$ World Conference on Co-operative Education - World Association of Co-operative Education (WACE) incorporating the $3^{\text {rd }}$ International Conference on Practice Orientated Education, North-eastern University, Boston USA, 14-17 June 2005.

[5] Hesketh T., 2002, “Chair's summary address of proceedings of IEAust Accreditation Visit for 2002 CQU Engineering ProgramS”, Institution of Engineers, Australia, Central Queensland. 